\title{
Prevalence of MDR and ESBL producing Gram- negative isolates from various clinical samples from patients visiting a tertiary care hospital in Kathmandu, Nepal
}

\section{Aryatara Shilpakar}

Shi-Gan Int'I College of Science and Technology

Mehraj Ansari ( $\sim$ mrseeyon@gmail.com )

Shi-Gan Int'I College of Science and Technology https://orcid.org/0000-0003-3396-9056

Kul Raj Rai

Institute of Microbiology Chinese Academy of Sciences

Ganesh Rai

Shi-Gan Int'I College of Science and Technology

Shiba Kumar Rai

Nepal Medical College

\section{Research Article}

Keywords: MDR, ESBL, Gram-negative isolates, carbapenems, polymyxin B, Nepal

Posted Date: February 17th, 2021

DOI: https://doi.org/10.21203/rs.3.rs-198444/v1

License: (c) (1) This work is licensed under a Creative Commons Attribution 4.0 International License. Read Full License

Version of Record: A version of this preprint was published at Tropical Medicine and Health on March 11th, 2021. See the published version at https://doi.org/10.1186/s41182-021-00313-3. 


\section{Prevalence of MDR and ESBL producing Gram-negative isolates from}

- ${ }^{1}$ Shi-Gan International College of Science and Technology (SICOST), Tribhuvan University, Kathmandu, Nepal,

- ${ }^{2}$ Institute of Microbiology, University of Chinese Academy of Sciences, China,

- $\quad{ }^{3}$ Nepal Medical College, Kathmandu, Nepal

\section{ABSTRACT}

\section{Background}

15 The existence of multi-drug resistance organisms, including extended-spectrum beta16 lactamases (ESBLs), is on the rise and is becoming a severe problem. Knowledge of the

17 prevalence and antibiogram profile of such isolates is essential to develop an appropriate treatment methodology. This study aimed to study the prevalence of Gram-negative isolates

19 exhibiting ESBL at a tertiary care hospital and study their antibiogram profile.

\section{Methods}

21 A cross-sectional study was conducted at Shahid Gangalal National Heart Centre, Kathmandu, Nepal, from June 2018 to November 2018. A total of 770 clinical samples were

23 collected and identified by using the conventional biochemical tests following the Clinical 24 and Laboratory Standard Institute (CLSI) guidelines. Antimicrobial susceptibility testing (AST) was performed using the Kirby Bauer disc diffusion method. The screening test for 
26 ESBL producers was performed as recommended by the CLSI and the confirmatory test was

27 performed phenotypically using the E-test.

\section{Results}

29 Out of 92 isolates, $84(91.3 \%)$ isolates were multidrug resistant, and $47(51.1 \%)$ isolates were

30 found to be potential ESBL producers. Of these, 16 isolates were confirmed ESBL producers

31 by the E-test. Escherichia coli and Klebsiella pneumoniae were the predominant isolates and 32 were also the major ESBL producers. Besides polymyxin B (100\% sensitive), meropenem 33 and imipenem showed high efficacy against the ESBL producers.

\section{Conclusion}

35 Multidrug resistance was very high, however, ESBL production was low. Polymyxin B and 36 carbapenems are the choice of drugs against ESBL producers but should be used only as the 37 last line drugs.

Keywords: MDR, ESBL, Gram-negative isolates, carbapenems, polymyxin B, Nepal

\section{BACKGROUND}

41 Although advancements in medical technology continue to grow, the combat against drug-

42 resistant microbes has always turned out to be challenging [1]. Bacteria have been ever-evolving

43 and conferring resistance to more advanced and powerful antibacterial drugs. For instance, ESBL

44 producers are capable of conferring resistance to beta-lactam antibiotics such as penicillins,

45 cephalosporins, aztreonam, and so forth [2]. Moreover, ESBL producers often carry genes

46 responsible for resistance to antimicrobial other than beta-lactamases, too [3]. Therefore, ESBLs

47 producers exhibit broad antibiotic resistance, which makes them problematic for clinical 
delayed antibiotic treatment, further increasing treatment costs [6]. The occurrence of ESBLs is

50 becoming more common in Gram-negative isolates [7,8] and the number of ESBL producers is

51 growing exponentially [9]. Many new classes of $\beta$-lactam antibiotics have been developed over

52 the years, but the overuse of such antibiotics has resulted in the emergence of new variants of $\beta$ -

53 lactamases [10]. Hence, ESBL producers have become a major multidrug-resistant pathogen in

54 the last two decades [11]. The problem is most noticeable in developing countries [1,11] and is

55 due primarily to the haphazard use of antibiotics. And as expected, in Nepal, the prevalence is

56 high as have been reported during the recent past $[12,13,14,15]$. The last decade has witnessed

57 several significant changes in the ESBL producing isolates [11]. Hence, regular surveillance of

58 ESBL production is needed to guide appropriate antimicrobial therapy [16] and minimize the risk

of developing resistance with certain drugs soon [17]. Thus, we conducted a study to find out the

60 prevalence and antimicrobial susceptibility pattern of ESBL producing Gram-negative bacteria

61 isolated from different clinical samples at tertiary care hospitals.

\section{METHODS}

63 Study design

64 A hospital-based cross-sectional study was conducted for six months (June to November 2018) at

65 Shahid Gangalal National Heart Centre, Kathmandu, Nepal. Different clinical samples taken from

66 patients admitted in the hospital and also from visiting outpatient departments of the hospital were

67 included. In the case of urine and sputum, proper information about sample collection was given.

68 Improperly collected samples or those lacking proper labeling were excluded from the study.

69 Isolation and identification of the isolates

70 A total of 770 samples (urine: 250, sputum: 185, pus: 115, blood: 166, wound swab: 49, and 71 tissue: 5) were processed (cultured) following the CLSI guidelines. The specimens were cultured 
on nutrient agar, brain heart infusion (BHI) broth (only for blood samples), MacConkey agar, and blood agar. The isolates were identified based on colony morphology, Gram's stain result, and conventional biochemical methods [18].

\section{Antimicrobial susceptibility testing}

Antimicrobial susceptibility testing (AST) was done by the Kirby-Bauer disk diffusion technique

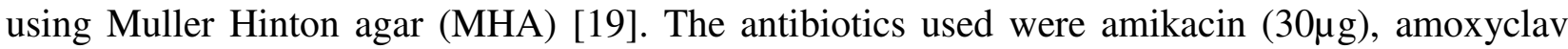
(30 $\mu \mathrm{g})$, amoxicillin $(10 \mu \mathrm{g})$, gentamicin $(10 \mu \mathrm{g})$, ceftriaxone $(30 \mu \mathrm{g})$, norfloxacin $(10 \mu \mathrm{g})$, cotrimoxazole $(25 \mu \mathrm{g})$, ciprofloxacin $(5 \mu \mathrm{g})$, cefixime $(30 \mu \mathrm{g})$, gentamicin $(10 \mu \mathrm{g})$, nitrofurantoin (30 $\mu \mathrm{g})$, nalidixic acid $(30 \mu \mathrm{g})$, ofloxacin $(5 \mu \mathrm{g})$, meropenem $(10 \mu \mathrm{g})$, piperacillin/tazobactam (100/10), polymyxin B (100 IU), imipenem (10 $\mu \mathrm{g})$, cefepime $(30 \mu \mathrm{g})$. The bacterial isolates showing resistance towards three or more different antibiotics classes were considered multidrugresistant (MDR) bacteria.

\section{Screening and confirmation of ESBL producers}

Ceftazidime, cefpodoxime, ceftriaxone, and cefotaxime were included in the primary panel for screening potential ESBL producers. Isolates showing resistance to any of these antibiotics were suspected as potential ESBL producers and were confirmed by E-test (Ezy MIC $\left.{ }^{\mathrm{TM}}\right)$. For this, a lawn culture of the test organism was done on MHA which the Ezy MIC ${ }^{\mathrm{TM}}$ strip was applied using the applicator, and reading was taken after incubation. Minimum inhibitory concentration (MIC) value (where the edge of the inhibition ellipse intersects the side of the strip) was noted. ESBL production was confirmed as positive when the ratio of the MIC value obtained for ceftazidime or ceftriaxone in combination with the clavulanic acid (CAZ+ or CTR+) was more than 8 or when no zone obtained for CTR or CAZ and zone obtained in CTR+ or CAZ+.

\section{Quality control}

All batches of the culture media and chemical reagents were processed with aseptic techniques following CLSI guidelines applying a standard aseptic procedure. In AST, quality control was maintained by using the control strains of E. coli ATCC 25922. Quality control of Ezy MIC ${ }^{\text {TM }}$ 
strip was carried out by testing the strips with standard ATCC strains (E. coli ATCC 25922 and

99 Klebsiella pneumoniae ATCC 700603).

100 Data analysis

101 SPSS v16.0 was used for statistical analysis. Chi-square test was applied at 95\% CI among

102 demographic variables.

103 RESULTS

104 A total of 92 Gram-negative bacteria were isolated from various clinical specimens. $K$. 105 pneumoniae $(\mathrm{n}=35)$ and E. coli $(\mathrm{n}=29)$ were the predominant isolates. Highest number of the 106 organism was isolated from urine $(n=52)$ followed by sputum $(n=18)$ (Table 1). A total of 39 and

10750 organisms were isolated from the inpatient department and outpatient department, respectively.

108 The highest number of organisms were isolated from the age-group above 60 and the least from

109 the age-group 11-20 (Table 3). There was no significant difference in growth positivity between 110 males and females $(\mathrm{p}=0.134)$; however, growth positivity in urine was significantly higher in 111 females $(77.3 \%)$ than in males $(37.5 \%)(\mathrm{p}=0.012)$.

Table 1: Sample-wise distribution of isolates

\begin{tabular}{|c|c|c|c|c|c|c|c|}
\hline \multirow{2}{*}{ Microorganisms } & \multicolumn{6}{|c|}{ Specimens } & \multirow[b]{2}{*}{ Total } \\
\hline & Urine & Sputum & Pus & Blood & Wound & Tissue & \\
\hline E. coli & 28 & 0 & 0 & 1 & 0 & 0 & 29 \\
\hline K. pneumoniae & 15 & 11 & 3 & 2 & 2 & 2 & 35 \\
\hline P. aeruginosa & 1 & 3 & 0 & 2 & 0 & 0 & 6 \\
\hline Acinetobacter spp. & 5 & 4 & 1 & 3 & 1 & 0 & 14 \\
\hline Enterobacter spp. & 1 & 0 & 0 & 0 & 1 & 0 & 2 \\
\hline P.mirabilis & 2 & 0 & 0 & 0 & 0 & 0 & 2 \\
\hline S. marcescens & 0 & 0 & 2 & 0 & 1 & 1 & 4 \\
\hline Total & 52 & 18 & 6 & 8 & 5 & 2 & 92 \\
\hline
\end{tabular}

112

113 Antibiotic susceptibility pattern of Gram-negative isolates

114 Of the 20 different antibiotics used, polymyxin B was the most effective drug (100\% sensitivity),

115 whereas amoxicillin (3.3\% sensitivity) was the least effective (Table 2). In AST, 47 (51.1\%)

116 isolates showed resistance to one or more cephalosporin used and were suspected to be ESBL

117 producers. 
119 Of the 20 different antibiotics used against Gram-negative bacteria, polymyxin B showed $100 \%$

120 effectiveness to ESBL producers. Meropenem and imipenem were sensitive to around $75 \%$ of the

Table 2: Organism-wise antibiotic resistance pattern

\begin{tabular}{|c|c|c|c|c|c|c|c|}
\hline \multirow[b]{2}{*}{ Antibiotics } & \multicolumn{7}{|c|}{ Isolates } \\
\hline & $\begin{array}{l}\text { E. coli } \\
(\mathrm{n}=29)\end{array}$ & $\begin{array}{c}\text { K. pneumoniae } \\
(\mathrm{n}=35)\end{array}$ & $\begin{array}{c}P \text {. aeruginosa } \\
\qquad(\mathrm{n}=6)\end{array}$ & $\begin{array}{c}\text { Acinetobacter } \\
(\mathbf{n}=14)\end{array}$ & $\begin{array}{c}\text { Enterobacter } \\
(n=2)\end{array}$ & $\begin{array}{c}P . \text { mirabilis } \\
(\mathrm{n}=2)\end{array}$ & $\begin{array}{l}\text { S. marcescens } \\
(n=4)\end{array}$ \\
\hline Amoxycillin & $100.0 \%$ & $94.3 \%$ & $100.0 \%$ & $100.0 \%$ & $100.0 \%$ & $100.0 \%$ & $75.0 \%$ \\
\hline Amikacin & $34.5 \%$ & $77.1 \%$ & $50.0 \%$ & $78.6 \%$ & $100.0 \%$ & $0.0 \%$ & $50.0 \%$ \\
\hline Cipofloxacin & $96.6 \%$ & $88.6 \%$ & $66.7 \%$ & $100.0 \%$ & $0.0 \%$ & $100.0 \%$ & $50.0 \%$ \\
\hline Cotrimoxazole & $65.5 \%$ & $60.0 \%$ & $100.0 \%$ & $100.0 \%$ & $100.0 \%$ & $50.0 \%$ & $50.0 \%$ \\
\hline Gentamicin & $27.6 \%$ & $80.0 \%$ & $83.3 \%$ & $78.6 \%$ & $0.0 \%$ & $50.0 \%$ & $0.0 \%$ \\
\hline Nalidixic Acid & $100.0 \%$ & $97.1 \%$ & $100.0 \%$ & $92.9 \%$ & $100.0 \%$ & $100.0 \%$ & $25.0 \%$ \\
\hline Polymyxin B & $0.0 \%$ & $0.0 \%$ & $0.0 \%$ & $0.0 \%$ & $0.0 \%$ & $0.0 \%$ & $0.0 \%$ \\
\hline Ofloxacin & $96.6 \%$ & $88.6 \%$ & $66.7 \%$ & $100.0 \%$ & $0.0 \%$ & $100.0 \%$ & $50.0 \%$ \\
\hline Amoxyclav & $79.3 \%$ & $85.7 \%$ & $100.0 \%$ & $92.9 \%$ & $100.0 \%$ & $100.0 \%$ & $0.0 \%$ \\
\hline Ceftriaxone & $86.2 \%$ & $91.4 \%$ & $83.3 \%$ & $92.9 \%$ & $0.0 \%$ & $0.0 \%$ & $50.0 \%$ \\
\hline Cefixime & $100.0 \%$ & $91.4 \%$ & $100.0 \%$ & $100.0 \%$ & $0.0 \%$ & $0.0 \%$ & $25.0 \%$ \\
\hline Ceftazidime & $89.7 \%$ & $91.4 \%$ & $83.3 \%$ & $100.0 \%$ & $100.0 \%$ & $0.0 \%$ & $50.0 \%$ \\
\hline Piperacillin tazobactam & $20.7 \%$ & $77.1 \%$ & $50.0 \%$ & $78.6 \%$ & $0.0 \%$ & $50.0 \%$ & $0.0 \%$ \\
\hline Tobramycin & $44.4 \%$ & $80.0 \%$ & $40.0 \%$ & $78.6 \%$ & - & - & - \\
\hline Cefepime & $93.1 \%$ & $91.4 \%$ & $50.0 \%$ & $85.7 \%$ & $100.0 \%$ & $50.0 \%$ & $25.0 \%$ \\
\hline Meropenem & $24.1 \%$ & $60.0 \%$ & $50.0 \%$ & $64.3 \%$ & $0.0 \%$ & $0.0 \%$ & $0.0 \%$ \\
\hline Imipenem & $20.7 \%$ & $57.1 \%$ & $50.0 \%$ & $78.6 \%$ & $0.0 \%$ & $0.0 \%$ & $25.0 \%$ \\
\hline Nitrofurantoin & $24.1 \%$ & $74.3 \%$ & - & $85.7 \%$ & $100.0 \%$ & $100.0 \%$ & $50.0 \%$ \\
\hline Norfloxacin & $96.6 \%$ & $88.6 \%$ & $66.7 \%$ & $100.0 \%$ & $0.0 \%$ & $100.0 \%$ & $50.0 \%$ \\
\hline Cephodoxime & $93.1 \%$ & $100.0 \%$ & $83.3 \%$ & $78.6 \%$ & $100.0 \%$ & $100.0 \%$ & $50.0 \%$ \\
\hline
\end{tabular}

122 fourth of the ESBL producers. Amoxycillin and Gentamicin were also effective against more than

123 three-fifths of the ESBL producers. All other antibiotics used showed reduced sensitivity to the

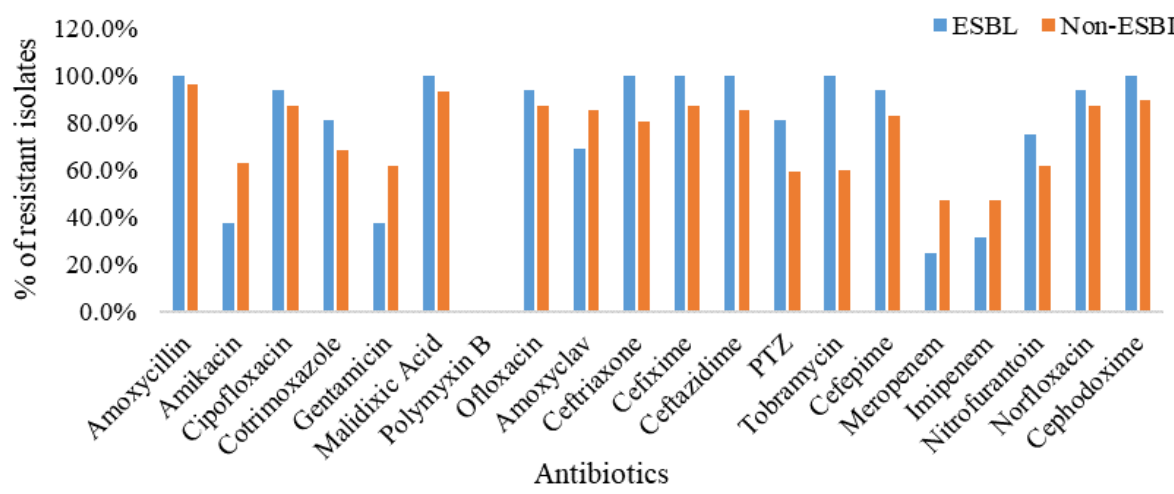

Fig 1: Antibiotic resistance pattern of the ESBL and non-ESBL producers 
130 ESBL producers as compared to the non-ESBL producing isolates (Fig 1).

\section{Distribution of ESBL producers in Gram-negative isolates}

132 Among the 47 suspected isolates, 16 (34.0\%) were found to be ESBL producers. ESBL

133 production was the highest in E. coli (39.3\%), followed by Acinetobacter and K. pneumoniae.

134 Other Gram-negative isolates, such as Pseudomonas aeruginosa, Enterobacter spp., Proteus

135 mirabilis, and Serratia marcescens, did not show any ESBL activity (Fig 2).

136

Distribution of MDR isolates and ESBL producers among total isolates

137

138

140
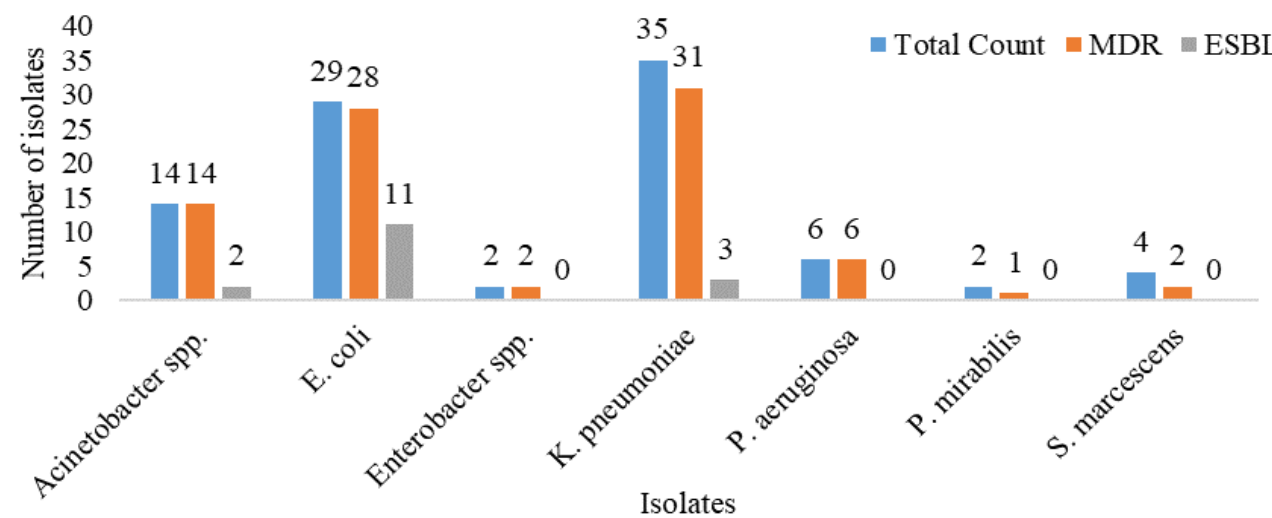

Fig 2: Distribution of MDR isolates and ESBL producers among total isolates.

Demographic distribution of MDR isolates and ESBL producers

The prevalence of MDR was higher in males, whereas ESBL production was dominant in females. MDR prevalence was very high in all age groups. ESBL production was higher in the age-groups 31-40 years and 41-50 years. The percentage of MDR isolates was higher in outpatient compared to the inpatient, whereas ESBL production was higher in isolates from inpatient than the outpatient. Among the samples, MDR was seen very high, i.e., $80 \%$ or above, in isolates from all the samples except pus. ESBL producers were dominant in urine and absent in pus, wound, and tissue samples (Table 3).

\section{DISCUSSION}

153 In this study, $11.9 \%$ of the samples showed growth positivity. However, higher rates of growth

154 positivity have been reported in similar studies in Nepal $[20,21,22,23]$. In this study, the highest number of growth was observed in the urine sample which was in agreement with that reported by 
$156 \mathrm{GC}$ et al. [21] and Gurung et al. [24]. K. pneumoniae was the dominant isolate, followed by $E$.

157 coli and Acinetobacter spp. GC et al. [21], Aryal et al. [22], and Guragain et al. [25] reported a 158 higher prevalence of $E$. coli followed by $K$. pneumoniae. Karn et al. [20] reported a lower 159 prevalence of $K$. pneumoniae and $P$. aeruginosa than ours. Similar culture positivity was seen in 160 both sexes; however, culture positivity was higher for females than males in the urine sample, and

161 a higher prevalence of E. coli and $K$. pneumoniae was observed. Similar outcomes were drawn by

162 Saderi et al. [26] and Yadav and Prakash [27]. Another study by Shrestha et al. [28] also unveiled 163 E. coli as the most common organism.

Table 3: Demographic distribution of MDR isolates and ESBL producers

\begin{tabular}{|c|c|c|c|c|c|}
\hline Characters & $\begin{array}{c}\text { Growth positive } \\
\qquad \mathrm{N}(\%)\end{array}$ & $\begin{array}{l}\text { MDR } \\
\text { N (\%) }\end{array}$ & p-value & $\begin{array}{c}\text { ESBL producers } \\
\mathrm{N}(\%)\end{array}$ & p-value \\
\hline \multicolumn{6}{|l|}{ Sex } \\
\hline Male $(n=424)$ & $48(11.3 \%)$ & $46(95.8 \%)$ & \multirow{2}{*}{0.146} & $7(14.6 \%)$ & \multirow{2}{*}{0.436} \\
\hline Female $(n=346)$ & $44(12.7 \%)$ & $38(86.4 \%)$ & & $9(20.5 \%)$ & \\
\hline \multicolumn{6}{|l|}{ Age-group } \\
\hline$<10(\mathrm{n}=123)$ & $12(9.8 \%)$ & $12(100 \%)$ & \multirow{7}{*}{0.77} & $2(16.7 \%)$ & \multirow{7}{*}{0.596} \\
\hline $11-20(\mathrm{n}=90)$ & $4(4.4 \%)$ & $3(75 \%)$ & & $0(0.0 \%)$ & \\
\hline $21-30(\mathrm{n}=84)$ & $9(10.7 \%)$ & $8(88.9 \%)$ & & $1(11.1 \%)$ & \\
\hline $31-40(n=105)$ & $21(20.0 \%)$ & $20(95.2 \%)$ & & $5(23.8 \%)$ & \\
\hline $41-50(\mathrm{n}=71)$ & $8(11.3 \%)$ & $7(87.5 \%)$ & & $3(37.5 \%)$ & \\
\hline $51-60(101)$ & $11(10.9 \%)$ & $10(90.9 \%)$ & & $2(18.2 \%)$ & \\
\hline$>60(\mathrm{n}=196)$ & $27(13.8 \%)$ & $24(88.9 \%)$ & & $3(11.1 \%)$ & \\
\hline \multicolumn{6}{|l|}{ Department } \\
\hline Inpatient $(\mathrm{n}=503)$ & $33(6.6 \%)$ & $27(81.8 \%)$ & \multirow{2}{*}{0.016} & $7(21.2 \%)$ & \multirow{2}{*}{0.693} \\
\hline Outpatient $(\mathrm{n}=197)$ & $59(29.9 \%)$ & $57(96.6 \%)$ & & $9(15.3 \%)$ & \\
\hline \multicolumn{6}{|l|}{ Sample } \\
\hline Urine $(\mathrm{n}=250)$ & $52(20.8 \%)$ & 47 (90.4\%) & \multirow{6}{*}{0.195} & $12(23.1 \%)$ & \multirow{6}{*}{0.714} \\
\hline Sputum $(n=185)$ & $18(9.7 \%)$ & $18(100 \%)$ & & $3(16.7 \%)$ & \\
\hline Pus (n=115) & $6(5.2 \%)$ & $4(66.6 \%)$ & & $0(0.0 \%)$ & \\
\hline Blood $(n=166)$ & $8(4.8 \%)$ & $8(100 \%)$ & & $1(12.5 \%)$ & \\
\hline Wound $(n=49)$ & $5(10.2 \%)$ & $4(80 \%)$ & & $0(0.0 \%)$ & \\
\hline Tissue $(\mathrm{n}=5)$ & $3(60.0 \%)$ & $2(66.7 \%)$ & & $0(0.0 \%)$ & \\
\hline $\mathrm{n}=770$ & $\mathrm{n}=92(11.9 \%)$ & $\mathrm{n}=84(91.3 \%)$ & & $\mathrm{n}=16(17.4 \%)$ & \\
\hline
\end{tabular}

164 More than $90 \%$ of the Gram-negative isolates showed multi-drug resistance in this study. MDR

165 was high in all the demographic characters studied. Most of the studies reported a lower MDR 
166 than this study [15,29]. Panta et al. [30] have shown MDR rate in 100\% of Klebsiella spp., and

$16780 \%$ of Acinetobacter spp. A study by Ghimire et al. [14] and Yadav et al. [31] recorded 96.8\%

168 and $82.5 \%$ of the isolates as MDR, respectively. Guragain et al. [25], Chakravarti et al. [32] and,

169 Sharma et al. [33], reported a lower MDR rate than ours in urinary E. coli and K. pneumoniae

170 isolates. Surprisingly, in our study, the percentage of MDR was seen higher in outpatients than

171 inpatients which is in contrast with that reported by Shrestha et al. [28]. The increasing rate of

172 MDR in outpatients found in this study might be due to non-empirical use, taking incomplete

173 doses of antibiotics, and the easy availability of antibiotics without prescription.

174 ESBL producing bacteria are gradually increasing in hospital sectors, mostly as nosocomial

175 infections, worldwide, and the occurrence of ESBL producing strains is changing rapidly over

176 time with great variation [34]. In this study, ESBL producing bacteria was $17.4 \%$ of the total

177 isolates. Kayastha et al. [15] and Raut et al. [35] reported a slightly higher prevalence of ESBL

178 producing organisms whereas Yadav and Prakash [27], Biswas et al. [36], and Afridi et al. [37]

179 reported a much higher rate. In this study, a greater number of ESBL producers were encountered

180 from inpatients (21.2\%) than outpatients (15.3\%). Similar findings have been reported by Mishra

181 et al. [12], and Khanfar et al. [38]. In this study, the highest ESBL producer was found in urine

$182(25.5 \%)$ followed by sputum (16.7\%) and blood (12.5\%). This was consistent with the reports

183 reported by Luzzaro et al. [7], Parajuli et al. [13], and Khanfar et al. [38] where the major source

184 of ESBL producers were urinary tract infections. Sharma et al. [33], however, reported a slightly

185 lower and Guragain et al. [25] reported a slightly higher rate of ESBL producing bacteria among

186 the urinary isolates. Over one-third of E. coli was found to be the major ESBL producing isolate

187 in this study and this was similar to that reported by Parajuli et al. [13], Ghimire et al. [14]. Yadav

188 et al. [31] and Khanfar et al. [38] have also highlighted E. coli as the major ESBL producing

189 bacteria. Kazemian et al. [39] reported higher ESBL production rates in E.coli, and $K$.

190 pneumoniae than ours, whereas Sharma et al. [33] reported lower ESBL production in both

191 strains. A study from Europe showed considerable variation, ranging from 1.6\% (Latvia) to $23.2 \%$ 
192 (Russia), in the prevalence of ESBL-producing E. coli isolates [40]. The change in ESBL

193 production pattern in bacteria seemed common as ESBLs were most often encoded on plasmids,

194 which could easily be transferred between isolates [41,42].

195 In this study, most of the first-line drugs were found to be ineffective. Antibiotics belonging to

196 third and fourth-generation cephalosporins, fluoroquinolones, amoxicillin, and amoxyclav were

197 found to be ineffective to ESBL producers and MDR strains. Khanfar et al. [38] have reported

198 high levels of resistance to gentamicin, amikacin, amoxicillin-clavulanic acid, and ciprofloxacin.

199 However, our findings showed greater susceptibility to amikacin and gentamicin. This might be

200 due to the minimal use of such drugs for treatment. On the contrary, the high degree of resistance

201 to cephalosporins and fluoroquinolones in our study might be due to over-dependent on such

202 antibiotics. Ogefere et al. [43] have also reported a high level of resistance against amoxicillin-

203 clavulanate, ceftazidime, ceftriaxone, gentamicin, ciprofloxacin, and ofloxacin by ESBL

204 producers. The overall antibiogram of Gram-negatives in this study showed a decreased

205 susceptibility against most of the antibiotics, including carbapenems. This might be due to the

206 haphazard use of the drug in hospital settings and unnecessary prescriptions by physicians before

207 the arrival of actual culture and sensitivity reports. A higher sensitivity was seen for polymyxin B

$208(100 \%)$ and carbapenems in ESBL producers in our study. Higher sensitivity to carbapenems was

209 also reported by Luzzaro et al. [7], Mishra et al. [12], Ghimire et al. [14], Shrestha et al. [28],

210 Biswas et al. [36] and, Khanfar et al. [38] making them an ideal choice of drugs so far, for treating

211 bacteria producing ESBL. All isolates showed sensitivity to polymyxin B. However, $K$.

212 pneumoniae, $P$. aeruginosa, and Acinetobacter spp. showed greater resistance against most of the

213 drugs except polymyxin B. All E. coli were sensitive to polymyxin B followed by imipenem.

214 Polymyxin B and carbapenems seem to be the choice of drugs against ESBL producers and Gram-

215 negative bacteria. However, these drugs should be considered as alternatives until we have other

216 effective drugs that could be administered safely. As the drug sensitivity pattern of different 
217 common Gram-negative bacteria seemed to change over time, a recent antibiogram for different

218 Gram-negative isolates might help physicians in treating bacterial infections [44].

\section{CONCLUSIONS}

220 The present study revealed a very high MDR prevalence (91.3\%) though ESBL production

221 (19.0\%) was low. Therefore, regular surveillance of MDR and ESBL producers and

222 implementation of hospital infection control policies to prevent the transmission of such isolates

223 is much required. Polymyxin B and carbapenems seem to be the choice of drugs against ESBL

224 producers and Gram-negatives but should be considered as alternatives until we have other

225 sensitive drugs that could be administered safely.

\section{Limitations}

227 There were a few limitations to our study. Firstly, the sample size was around 770, which seemed 228 to be significantly less than in other studies. The study was conducted within a short duration, i.e., 229 six months. The data taken was purely obtained from only one hospital, which might not represent 230 the whole population. Only a phenotypic study was performed. Studies on the molecular level 231 would have strengthened the findings.

\section{List of abbreviations}

233 ESBL: Extended-spectrum beta-lactamase, CLSI: Clinical and Laboratory Standard Institute,

234 MDR: Multidrug Resistant, BHI: Brain Heart Infusion, MHA: Muller Hinton Agar, ATCC:

235 American Type Culture Collection, E. coli: Escherichia coli, K. pneumoniae: Klebsiella 236 pneumoniae, CI: Confidence Interval

\section{Declarations}

\section{Ethical approval and consent to participate}

239 The ethical consideration was obtained from the Research Review Committee of the National

240 Institute of Tropical Medicine and Public Health Research (NITMPHR) center, Research, and

241 Ethical committee, Shi-Gan, and NITMPHR Health Foundation Maharajgunj, Kathmandu, Nepal 242 (IRC Reference No: 04/2071/08/26). Written informed consent was obtained from all the 
243 participants above age 16 and the parent of children under 16 years before sample collection. All

244 methods were carried out under relevant guidelines and regulations.

\section{Consent for publication}

246 Not applicable

\section{Availability of data and materials}

248 The datasets generated and analyzed during the current study are available in the appropriate 249 materials repository (tables and figures).

\section{Competing interests}

251 The authors declared no conflicts of interest to the research, authorship, and publication of this 252 article.

\section{Funding}

254 The authors received no financial support for the study, authorship, and publication of this article.

\section{Authors' Contribution}

256 All authors made substantial contributions to conception and design, research work, data analysis; took part in drafting the article or revising it; gave final approval of the version to be published; and agreed to be accountable for all aspects of the work.

\section{Acknowledgments}

260 We would like to acknowledge the laboratory staff and research participants of ANIAS for their 261 help and support. We are equally grateful to all the colleagues to all the people who directly or 262 indirectly helped in completing this work.

\section{REFERENCES}

265 1. Aslam B, Wang W, Arshad MI, Khurshid M, Muzammil S, Rasool MH et al. Antibiotic resistance: a rundown of a global crisis. Infect Drug Res 2018;11:1645-8.

2. Paterson DL and Bonomo RA. Extended-spectrum $\beta$-lactamases: A clinical update. Clin Microbiol Rev. 2005; 18 Suppl 4:657-86. 
3. Peterson DL. Recommendation for treatment of severe infections caused by Enterobacteriaceae producing extended-spectrum beta-lactamases (ESBL). Clin Microbiol Infect. 2000;6:460-3.

272

4. Mammeri H, Loo MV, Poirel L, Martinez L, and Nordmann P. Emergence of plasmidmediated quinolone resistance in E. coli in Europe. Antimicrob Agents Chemother. 2005; 49 Suppl 1:71-6.

5. Wang M, Sahm DF, Jacoby GA, and Hooper AD. Emerging plasmid-mediated quinolone resistance associated with the qnr gene in K. pneumoniae clinical isolates in the United States. Antimicrob Agents Chemother. 2004;48 Suppl 4:1295-9.

6. Knudsen JD, and Andersen SE. A Multidisciplinary intervention to reduce infections of ESBL- and AmpC-producing Gram-negative bacteria at a University Hospital. PLOS ONE 2014;9(1):e86457. doi:10.1371/journal.pone.0086457.

7. Luzzaro F, Mezzatesta M, Mugnaioli C, Perilli M, Stefani S, Amicosante G et al. Trends in production of extended-spectrum $\beta$-lactamases among Enterobacteria of medical interest: Report of the Second Italian Nationwide Survey. J Clin Microbiol. 2004;44:1659-64.

8. Song W, Kim J, Bae IK, Jeong SH, Seo YH, Shin JH et al. Chromosome-encoded AmpC and CTX-M extended-spectrum $\beta$-lactamases in clinical isolates of $P$. mirabilis from Korea. Antimicrob Agents Chemother. 2011;55:1414-9.

9. Sid Ahmed MA, Bansal D, Acharya A, Elmi AA, Hamid JM, Sid Ahmed AM et al. Antimicrobial susceptibility and molecular epidemiology of extended-spectrum betalactamase-producing Enterobacteriaceae from intensive care units at Hamad Medical Corporation, Qatar. Antimicrob Resist Infect Control. 2016;5:4. doi:10.1186/s13756-0160103-x.

10. Agrawal P, Ghosh AN, Kumar S, Basu B, and Kapila K. Prevalence of extended-s[ectrum Blactamases among E. coli and $K$. pneumoniae isolates in a tertiary care hospital. Indian $\mathbf{J}$ Pathol Microbiol. 2008;51:139-42.

11. Doi Y, Lovleva A, and Bonomo RA. The ecology of extended-spectrum B-lactamases (ESBLs) in the developed world. J Travel Med. 2017;24 Suppl 1:44-51.

12. Mishra SK, Sapkota GP, Adhikari S, and Lakhey M. Beta-lactamases in a Nepalese hospital: wake up before the "biological quake" destroys you. Int J Infect Dis. 2016;45S:103. lactamase producing Enterobacteriaceae clinical isolates in a Teaching Hospital of Nepal. BioMed Res Int. 2016;3:1-7. 
14. Ghimire A, Acharya B, and Tuladhar R. Extended spectrum $\beta$-lactamase (ESBL) producing multidrug-resistant Gram-negative bacteria from various clinical specimens of patients visiting a tertiary care hospital. TU J Microbiol. 2018;4 Suppl 1:1-8.

15. Kayastha K, Dhungel B, Karki S, Adhikari B, Banjara MR, Rijal KR, et al. Extendedspectrum $\beta$-lactamase-producing Escherichia coli and Klebsiella species in pediatric patients visiting International Friendship Children's Hospital, Kathmandu, Nepal. Infect Dis. 2020;13: $1-7$.

16. Gautam V, Thakur A, Sharma M, Singh A, Bansal S, Sharma A, et al. Molecular characterization of extended-spectrum B-lactamases among clinical isolates of Escherichia coli and Klebsiella pneumoniae: A multi-centric study from tertiary care hospitals in India. Indian J Med Res. 2019;149:208-15.

17. Li B, and Webster TJ. Bacteria antibiotic resistance: New challenges and opportunities for implant-associated orthopedic infections. J Orthop Res. 2018;36 Suppl 1:22-32.

18. Cheesbrough M: District laboratory practice in Tropical Countries. Part 2. Cambridge University Press. UK. 2000;62-70.

19. CLSI (Clinical and Laboratory Standards Institute). Performance standards for antimicrobial susceptibility testing; 19th informational supplement. Document M100-S29. Wayne, PA. 2010.

20. Karn S, Pant ND, Neupane S, Khatiwada S, Basnyat S, and Shrestha B. Prevalence of carbapenem-resistant bacterial strains isolated from different clinical samples: a study from a tertiary care hospital in Kathmandu, Nepal. J Biomed Sci. 2016;3 Suppl 1:11-5.

21. GC B, Sapkota NR, Rayamajhee B, Lamichhane J, Poudel P, Lekhak S, et al. Detection of blaNDM-1 gene among the carbapenem-resistant Escherichia coli and Klebsiella pneumoniae isolates from a children's hospital in Nepal. J Novel Research Microbiol. 2018;2 Suppl 5:6574.

22. Aryal SC, Upreti MK, Ansari M, Nepal K, Dhungel B, Adhikari N, et al. Plasmid-mediated AmpC $\beta$-lactamase CITM and DHAM genes among Gram-negative clinical isolates. Infect Drug Resist. 2020;3:4249-61.

23. Pokhrel H, Thapa B, Kafle R, Shah PK, and Tribuddharat C. Co-existence of beta-lactamases in clinical isolates of Escherichia coli from Kathmandu, Nepal. BMC Res Notes. 2014;7:694.

24. Gurung S, Kafle S, Dhungel B, Adhikari N, Shrestha U, Adhikari B, et al. Detection of OXA48 gene in carbapenem-resistant Escherichia coli and Klebsiella pneumoniae from urine samples. Infect Drug Resist. 2020;13:2311-21. 
25. Guragain N, Pradhan A, Dhungel B, Banjara MR, Rijal KR, and Ghimie P. Extendedspectrum beta-lactamase-producing Gram-negative bacterial isolates from the urine of patients visiting Everest Hospital, Kathmandu, Nepal. TU J Microbiol 2019;6 Suppl 1:26-31.

26. Saderi H, Owlia P, Nadoushan MRJ, Zaeri F, and Zandieh E. A 3-year study of demographic characteristics of patients with urinary tract infection, microbial etiology, and susceptibility of isolated bacteria to antibiotics in Shaheed Mostafa Khomeini Hospital. Iran J Pathol. 2006;1 Suppl 3:99-104.

27. Yadav $\mathrm{K}$ and Prakash S. Screening of ESBL producing multidrug-resistant E. coli from urinary tract infection suspected cases in Southern Terai of Nepal. J Infect Dis Diag. 2017;2 Suppl 2:1-8.

28. Shrestha D, Sherchand SP, Gurung K, Manandhar S, Shrestha B, and Sherchan S. Prevalence of multidrug-resistant extended-spectrum B-lactamase-producing bacteria from different clinical specimens in Kathmandu Model Hospital, Kathmandu, Nepal. EC Microbiol. 2016;4 Suppl 2:676-98.

29. Nepal K, Pant ND, Neupane B, Belbase A, Baidhya R, Shrestha RK, et al. Extended-spectrum beta-lactamase and Metallo beta-lactamase production among Escherichia coli and Klebsiella pneumoniae isolated from different clinical samples in a tertiary care hospital in Kathmandu, Nepal. Ann Clin Microbiol Antimicrob. 2017;16 Suppl 1:62.

30. Panta K, Ghimire P, Rai SK, Mukhiya RK, Singh R, and Rai G. Antibiogram typing of Gramnegative isolates in different clinical samples of a tertiary hospital. Asian J Pharm Clin Res. 2016;6 Suppl 1:1153-6.

31. Yadav KK, Adhikari N, Khadka R, Pant AD, and Shah B. Multidrug-resistant Enterobacteriaceae and extended-spectrum $\beta$-lactamase producing Escherichia coli: a crosssectional study in National Kidney Center, Nepal. Antimicrobial Resist Infect Control 2015;4(42):1-7.

32. Chakrawarti A, Dongol P, Khanal H, Subba P, and Banerjee JJ. Extended-spectrum betalactamases detection and multiple antibiotic resistance indexing of Escherichia coli from urine samples of patients from a referral hospital of Eastern Nepal. Int J Appl Sci Biotechnol 2015; 3 Suppl 3:423-6.

33. Sharma KR, Bhandari P, Adhikari N, Tripathi P, Khanal S, and Tiwari BR. Extendedspectrum $\beta$-lactamase (ESBL) producing multi-drug resistant (MDR) urinary pathogens in a children's hospital from Nepal. Kathmandu Univ Med J 2018; 16(62):151-5.

34. Chander A, and Shrestha CD. Prevalence of extended-spectrum beta-lactamase-producing Escherichia coli and Klebsiella pneumoniae urinary isolates in a tertiary care hospital in Kathmandu, Nepal. BMC Res Notes 2013;6:487. 
35. Raut S, Gokhale S, and Adhikari B. Prevalence of extended spectrum beta-lactamases among Escherichia coli and Klebsiella spp isolates in Manipal Teaching Hospital, Pokhara, Nepal. J Microbiol Infect Dis. 2015;5 Suppl 2:69-75.

36. Biswas SM, Ara N, Huda N, Andalib S, Rahman MH, and Mia MRA. Detection and antimicrobial susceptibility pattern of extended spectrum beta-lactamases (ESBLs) producing Gram-negative bacteria from different clinical samples. Puls. 2015;8:15-20.

37. Afridi FI, Farooqi BJ, and Hussain A. Frequency of extended-spectrum beta-lactamase producing Enterobacteriaceae among urinary pathogen isolates. J Coll Physicians Surgs Pak 2011;21 Suppl 12:741-4.

38. Khanfar HS, Bindayna KM, Senok AC, and Botta GA. ESBL-producers in the hospital and community settings J Infect Dev Ctries. 2009;3(4):295-9.

39. Bradford PA, Cherubin CE, Idemyor V, Rasmussen BA, and Bush K. Multiply resistant $K$. pneumoniae strains from two Chicago Hospitals: identification of the extended-spectrum TEM-12 and TEM-10 Ceftazidime-hydrolyzing $\beta$-lactamases in a single isolate. Antimicrob Agents Chemother. 1994;38:761-6.

40. Kazemian H, Heidari H, Ghanavati R, Ghafourian S, Yazdani F, Sadeghifard N, et al. Phenotypic and genotypic characterization of ESBL-, AmpC-, and carbapenemase-producing Klebsiella pneumoniae and Escherichia coli isolates. Med Princ Pract. 2019;28:547-51.

41. Ny S, Kozlov R, Dumpis U, Edquist P, Hannuksela KGY, Kling AM, et al. Large variation in ESBL-producing Escherichia coli carries in six European countries including Russia. Eur J Clin Microbiol Infect Dis. 2018;37:2347-54.

42. Wiener J, Quinn JP, Bradford PA, Goering RV, Nathan C, Bush K, and Weinstein RA. Multiple antibiotic-resistant K. and E. coli in nursing homes. JAMA. 1999;281:517-23.

43. Ogefere HO, Aigbiremwen PA, and Omoregie R (2015). Extended-Spectrum Beta-Lactamase (ESBL)-Producing Gram-negative Isolates from Urine and Wound Specimens in a Tertiary Health Facility in Southern Nigeria. Trop J Pharm Res. 2015;14(6):1089-94.

44. Moehring RW, Hazen KC, Hawkins MR, Drew RH, Sexton DJ, and Anderson DJ (2015). Challenges in Preparation of Cumulative Antibiogram Reports for Community Hospitals. J Clin Microbiol. 2015;53(9):2977-82. 


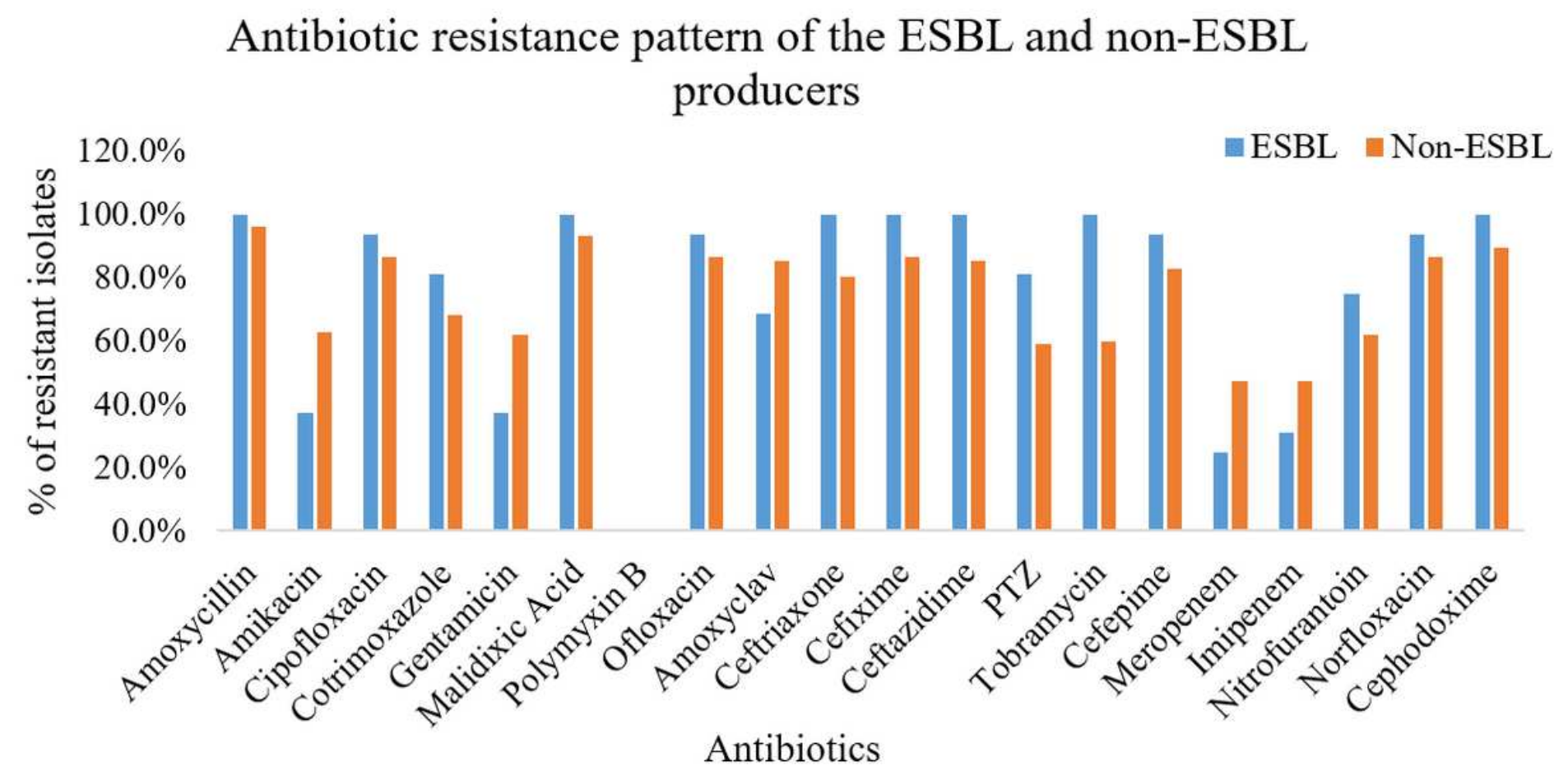

Figure 1

Antibiotic resistance pattern of the ESBL and non-ESBL producers

Distribution of MDR isolates and ESBL producers among total isolates

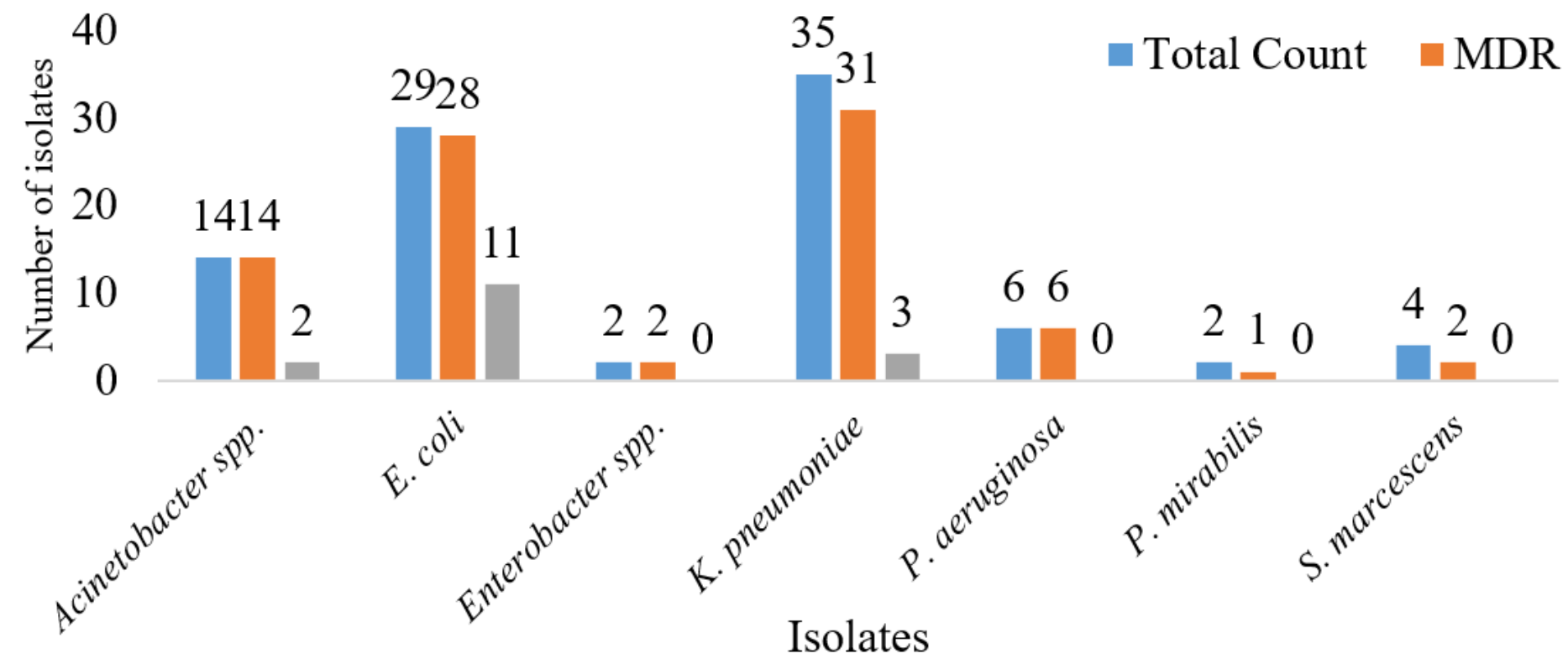

Figure 2 
Distribution of MDR isolates and ESBL producers among total isolates. 